\title{
A new diagnostic algorithm for assessment of patients with single ventricle before a Fontan operation
}

\author{
Ashwin Prakash, MD, Muhammad A. Khan, MD, Rose Hardy, BA, Alejandro J. Torres, MD, \\ Jonathan M. Chen, MD, and Welton M. Gersony, MD
}

\begin{abstract}
Objectives: Cardiac catheterization has a low diagnostic yield before a Fontan operation, and magnetic resonance imaging and computed tomography are reliable alternatives to invasive angiography. A new diagnostic algorithm to avoid cardiac catheterization in "low-risk" subjects before a Fontan operation is proposed.
\end{abstract}

\begin{abstract}
Methods: The proposed algorithm would identify "high-risk" subjects on the basis of risk factors on medical history, echocardiography, and noninvasive angiography. The efficacy of this algorithm in screening for subjects deemed to be inoperable after catheterization was evaluated retrospectively in 151 children. For this analysis, results of conventional angiography (assumed to be equivalent to noninvasive angiography) were used.
\end{abstract}

Results: According to the algorithm, 95 (63\%) of 151 subjects had no risk factors ("low risk") whereas 56 $(37 \%)$ of 151 had 1 risk factor or more ("high risk"). Nine (6\%) of 151 subjects were found to be inoperable after catheterization and all 9 were correctly classified as high risk by the algorithm. In the 135 of 151 subjects who underwent a Fontan operation, the algorithm predicted an adverse postoperative outcome with a sensitivity of $51 \%$ and specificity of $78 \%$. However, this prediction was not improved by including elevated pulmonary artery pressure or ventricular filling pressure as additional risk factors.

Conclusions: The proposed algorithm effectively screened for subjects who were deemed unsuitable for a Fontan procedure. In addition, omitting preoperative invasive hemodynamic assessment did not impair prediction of adverse postoperative outcomes. Prospective evaluation of such a noninvasive diagnostic strategy before the Fontan operation is warranted.

Earn CME credits at

http://cme.ctsnetjournals.org

The Fontan operation is the final surgical stage for most patients with a functionally single ventricle, resulting in a marked change in cardiovascular physiology. ${ }^{1}$ Since inception, detailed hemodynamic assessment and angiographic evaluation of the extracardiac thoracic vasculature by cardiac catheterization before surgery has been considered to be mandatory. However, for most other types of congenital heart disease, the use of preoperative catheterization has become infrequent. In part, this is due to the advent of newer noninvasive diagnostic techniques such as echocardiography, magnetic resonance imaging (MRI), and computed tomography $(\mathrm{CT})$ as reliable replacements for invasive $\mathrm{x}$-ray

\footnotetext{
From the Division of Pediatric Cardiology, Columbia University College of Physicians and Surgeons, New York, NY.

Presented in part at the Annual Scientific Sessions of the American College of Cardiology, 2007.

Received for publication Oct 21, 2008; revisions received Feb 9, 2009; accepted for publication March 9, 2009; available ahead of print June 1, 2009.

Address for reprints: Ashwin Prakash, MD, Department of Cardiology, Children's Hospital, 300 Longwood Ave, Boston, MA 02115 (E-mail: ashwin.prakash@ cardio.chboston.org).

J Thorac Cardiovasc Surg 2009;138:917-23

$0022-5223 / \$ 36.00$

Copyright (c) 2009 by The American Association for Thoracic Surgery

doi:10.1016/j.jtcvs.2009.03.022
}

angiography. ${ }^{2-6}$ Cardiac catheterization continues to be used routinely for children who are referred for a Fontan operation to perform hemodynamic assessment for the possibility of elevated pulmonary artery pressure (PAP) or increased ventricular filling pressure (VFP), which can only be identified by invasive testing. However, in the modern era of timely staged palliation, it is unusual for patients with functionally single ventricle to be subjected to unrestrictive pulmonary blood flow and have significant pulmonary vascular disease with resultant pulmonary hypertension. Ventricular diastolic dysfunction is a risk factor for patients undergoing the Fontan operation, but it may be difficult to identify, especially with load-dependent parameters such as VFP. ${ }^{7}$

It is rare for a patient to be deemed unsuitable for a Fontan operation as a result of routine invasive hemodynamic testing in the absence of known risk factors. ${ }^{8}$ Thus, given the low yield of catheterization, it may be possible to limit hemodynamic testing to only high-risk subjects who have been identified by clinical criteria and noninvasive techniques. However, it is not known whether using such an approach would allow the identification of all subjects who are inoperable. It is also not known whether the omission of routine invasive hemodynamic testing in low-risk patients would impair the ability to predict adverse postoperative outcomes.

As a first step toward answering these questions, in the present study, we developed a diagnostic algorithm for assessment of patients before a Fontan operation. In this 


$$
\begin{aligned}
& \text { Abbreviations and Acronyms } \\
& \text { CPB }=\text { cardiopulmonary bypass } \\
& \text { CT }=\text { computed tomography } \\
& \text { ICU }=\text { intensive care unit } \\
& \text { MRI }=\text { magnetic resonance imaging } \\
& \text { NPV }=\text { negative predictive value } \\
& \text { PAP }=\text { pulmonary artery pressure } \\
& \text { PPV }=\text { positive predictive value } \\
& \text { VFP }=\text { ventricular filling pressure }
\end{aligned}
$$

algorithm, invasive hemodynamic assessment is limited to only high-risk subjects who have been identified by screening for the presence of clinical risk factors and after assessment by noninvasive imaging. We hypothesized that (1) this new diagnostic algorithm can successfully identify subjects who are inoperable and (2) omission of invasive hemodynamic testing does not impair the ability to predict adverse postoperative outcomes in low-risk patients. We retrospectively tested the efficacy of this algorithm in a series of patients who had undergone routine cardiac catheterization to determine suitability for a Fontan operation.

\section{METHODS}

\section{Proposed Diagnostic Algorithm}

To consider the possibility of eliminating routine preoperative cardiac catheterization, one must develop an alternative diagnostic strategy that will provide data for assessing suitability for the operation and for predicting an adverse postoperative outcome. We developed such a diagnostic algorithm (Figure 1) for assessment before a Fontan operation on the basis of factors that have been shown to be associated with an increased risk of being inoperable or having adverse outcomes after a Fontan operation. ${ }^{9-15}$ In this algorithm, data from history, echocardiography, and noninvasive angiography (using MRI or CT) are used (Table 1). Subjects with 1 or more risk factors are classified as "high risk" and undergo conventional cardiac catheterization, whereas subjects without any risk factors are classified as "low risk" and undergo a Fontan operation without cardiac catheterization. Angiographic evaluation of the pulmonary vasculature and systemic venous anatomy is important because abnormalities in these areas are not reliably detected by echocardiography. Hence, several angiographic criteria are included in our algorithm. Owing to the retrospective nature of this study, noninvasive angiographic data from MRI or CT were not available. Hence, data from $\mathrm{x}$-ray angiography were used to identify angiographic risk factors. For the purpose of this study, it was assumed that MRI or CT imaging is equivalent to $\mathrm{X}$-ray angiography, as shown previously by numerous investigators. ${ }^{2-6,16}$

\section{Evaluation of Algorithm}

To test its diagnostic efficacy, we applied the diagnostic algorithm retrospectively to 151 consecutive children with a functionally single ventricle who underwent cardiac catheterization after the age of 1 year at the Morgan Stanley Children's Hospital of New York Presbyterian between 2000 and 2005, presumably to assess suitability for a Fontan operation. The Institutional Review Board of Columbia University Medical Center gave permission for the analysis of existing clinical data. Data recorded for each subject included the following: (1) presence of risk factors (Table 1) on history, echocardiography, and x-ray angiography performed at the time of referral for preoperative evaluation; (2) suitability for the Fontan operation as deter-

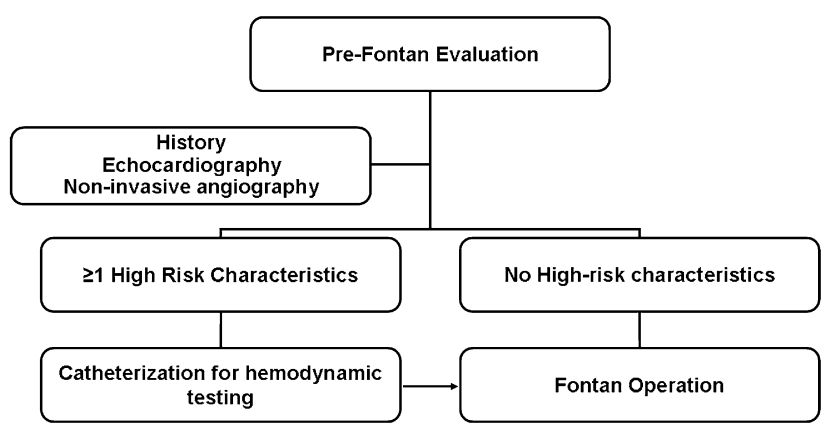

FIGURE 1. Proposed diagnostic algorithm: Characteristics on history, echocardiography, or noninvasive angiography are used to identify highrisk subjects. Low-risk subjects undergo the Fontan operation without preceding catheterization, whereas high-risk subjects undergo catheterization before the operation for hemodynamic testing.

mined by the subject's cardiologist, who had access to all available data, including results of cardiac catheterization; (3) PAP and VFP at cardiac catheterization; (4) interventional procedures performed at catheterization; and (5) for subjects who subsequently underwent a Fontan operation, details of the operation (type of Fontan, creation of a fenestration, duration of cardiopulmonary bypass), postoperative course (duration of intensive care unit [ICU] stay, and duration of pleural drainage), and data on survival to 1 year after the operation. An adverse postoperative outcome was defined as the occurrence of one or more of the following events: (1) death within 1 year of the operation; (2) prolonged pleural drainage ( $>15$ days); (3) prolonged ICU stay (>10 days); and (4) cardiac catheterization within a 3month period after the operation.

\section{Statistical Analyses}

Statistical analyses were performed with commercially available statistical software (STATA SE 9.0; Stata Corp, College Station, Tex). To evaluate the efficacy of the proposed diagnostic algorithm in identifying subjects who are inoperable, we calculated sensitivity, specificity, positive predictive value (PPV), negative predictive value (NPV), likelihood ratios, and post-test probability as previously described. ${ }^{17-19}$ We also generated $95 \%$ confidence intervals (CI) for sensitivity, specificity, PPV, and NPV. To evaluate the proposed diagnostic algorithm's efficacy in predicting adverse postoperative outcomes, we similarly calculated sensitivity, specificity, PPV, NPV, likelihood ratios, and post-test probabilities. To test the hypothesis that the omission of invasive hemodynamic testing does not impair the ability to predict adverse postoperative outcomes, we repeated the above analyses after including the presence of elevated PAP $(>15 \mathrm{~mm} \mathrm{Hg})$ and/or VFP $(>10 \mathrm{~mm} \mathrm{Hg})$ as additional risk factors in the proposed algorithm. Furthermore, to identify predictors of an adverse postoperative outcome as previously defined, we used multivariable logistic regression. Variables included for analysis were age at operation, PAP, VFP, ventricular dysfunction, atrioventricular valve regurgitation, creation of a fenestration, presence of heterotaxy or a defined genetic syndrome, cardiopulmonary bypass (CPB) time, and the type of Fontan operation (lateral tunnel or extracardiac conduit). In addition, further analyses were performed to identify predictors of the following individual outcomes: duration of ICU stay, duration of pleural drainage, and death within 1 year after operation. Data for duration of ICU stay and duration of pleural drainage were skewed and underwent logarithmic transformation before analysis to satisfy normalcy requirements. Multivariable linear regression was used to identify the predictors of log-transformed duration of ICU stay and log-transformed duration of pleural drainage, and multivariable logistic regression was used to identify predictors of death within 1 year after operation. For all multivariable modeling using either logistic or linear regression, a "backward elimination" method was used for selection of variables and $P<.05$ was required for inclusion of a variable in the final model. 
TABLE 1. Characteristics of high-risk subjects

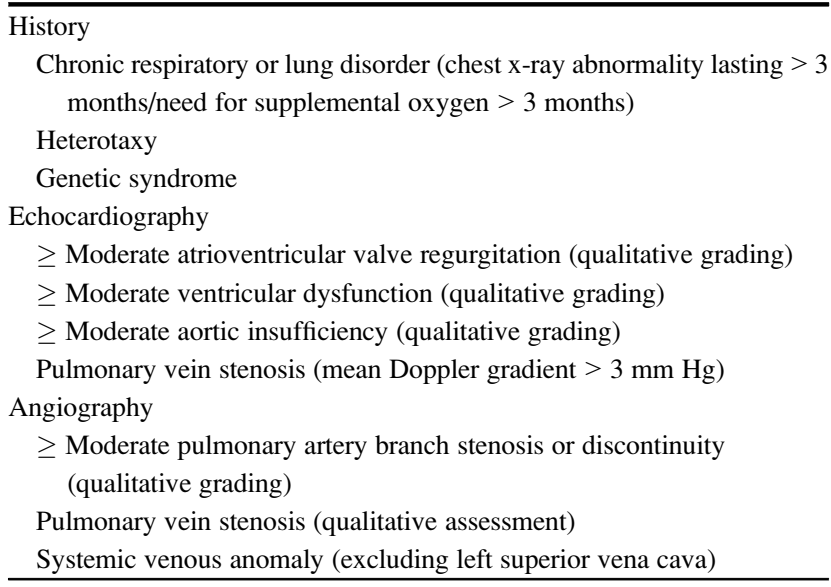

\section{RESULTS}

A total of 151 consecutive children ( $63 \%$ male) who underwent cardiac catheterization for assessment before a Fontan operation between 2000 and 2005 at Children's Hospital of New York Presbyterian were included in this study. Subject diagnoses are shown in Table 2. Hypoplastic left heart syndrome was the most common diagnosis, in approximately one third of the subjects. A majority (147/151, $97 \%$ ) of subjects had undergone a superior cavopulmonary anastomosis with either a bidirectional Glenn $(\mathrm{n}=117)$ or hemi-Fontan $(\mathrm{n}=30)$ operation. According to the proposed algorithm, $95(63 \%)$ subjects had no risk factors (low-risk group) and $56(37 \%)$ had 1 or more risk factors (high-risk group).

\section{Identification of Inoperable Subjects by the Proposed Algorithm (Figure 2)}

A total of 9 subjects were deemed inoperable for the Fontan operation by their cardiologist after undergoing cardiac catheterization. The proposed algorithm performed well in screening for inoperability, and all of the 9 inoperable subjects were correctly classified in the high-risk group. However, 47 eligible subjects were also classified as high risk. In identifying inoperable subjects, the algorithm's sensitivity $(100 \%, 95 \%$ CI $66-100)$ and NPV $(100 \%, 95 \%$ CI $97-100)$ were high whereas the specificity $(67 \%, 95 \%$ CI 59-75) and PPV (16\%, 95\% CI 8-28) were low. For a subject classified as high risk by the algorithm, the likelihood ratio was 3.03 and the post-test probability of being inoperable was $19 \%$ (increased from a pre-test probability of $6 \%$ ). On the other hand, for a subject classified as low risk by the algorithm, the likelihood ratio was 0.015 (assuming a sensitivity of $99 \%$ instead of the actual $100 \%$ to allow calculation) and post-test probability of being inoperable was $0.1 \%$ (decreased from a pre-test probability of $6 \%$ ). The characteristics of the 9 subjects who were inoperable are described in Table 3. All inoperable subjects had risk factors on history, echocardiography, or angiography and 6 of the 9 had abnor-
TABLE 2. Subject characteristics

\begin{tabular}{ll}
\hline \multicolumn{1}{c}{ Diagnosis } & $\mathbf{N}$ \\
\hline Hypoplastic left heart syndrome & $53(35 \%)$ \\
Unbalanced atrioventricular canal defect & $26(17 \%)$ \\
Double-inlet left ventricle & $18(12 \%)$ \\
Tricuspid atresia & $17(11 \%)$ \\
Pulmonary atresia with intact ventricular septum & $12(8 \%)$ \\
Others & $25(17 \%)$ \\
\hline
\end{tabular}

mal PAP and/or VFP. Several subjects had multiple risk factors. No inoperable subject had an elevated PAP and/or VFP without an associated risk factor on history, echocardiography, or angiography.

\section{Subjects Who Underwent a Fontan Operation}

At the time of data analysis, 135 of the 142 operable subjects had undergone the Fontan operation at a median age of 3.2 years (interquartile range $2.5-3.9$ years).

Preoperative characteristics. Of the 135 subjects who underwent a Fontan operation, 95 were in the low-risk group and 40 were in the high-risk group. PAP and VFP were similar in the low-risk $(11 \pm 3$ and $9 \pm 2 \mathrm{~mm} \mathrm{Hg})$ and high-risk groups (12 \pm 3 and $9 \pm 3 \mathrm{~mm} \mathrm{Hg} ; P>.5$ for both). In the low-risk group, $24(27 \%)$ children had an elevated PAP $(>15 \mathrm{~mm} \mathrm{Hg}, \mathrm{n}=7)$ and/or VFP $(>10 \mathrm{~mm} \mathrm{Hg}, \mathrm{n}=23)$, whereas in the high-risk group, $22(55 \% ; P=.0009$ using a 2-sided Student $t$ test) had an elevated PAP $(\mathrm{n}=5)$ and/ or VFP $(n=22)$. However, no patient undergoing a Fontan operation had a PAP greater than $23 \mathrm{~mm} \mathrm{Hg}$ or a VFP greater than $14 \mathrm{~mm} \mathrm{Hg}$.

Operative details and early postoperative outcomes. The Fontan operation was performed with a lateral tunnel in $99(74 \%)$ and an extracardiac conduit in $35(26 \%)$ subjects. A fenestration was performed in $81(60 \%)$ subjects. Within the first month after the operation, there were 2 deaths and 1 patient required heart transplantation. Median duration of stay in the ICU was 6 days (interquartile range 4-8 days). Median duration of pleural drainage was 9 days (interquartile range 7-12 days). An adverse postoperative outcome as previously defined occurred in $26 \%$ (95\% CI $19-34 \%$ ) of subjects.

Prediction of postoperative outcomes using the algorithm with and without additional hemodynamic data. As seen in Table 4, the proposed algorithm had modest success in predicting adverse postoperative outcomes. Compared with the entire study population, presence in the high-risk group increased the probability of an adverse outcome whereas presence in the low-risk group decreased the probability of an adverse outcome. The occurrence of an adverse postoperative outcome was significantly associated with a high-risk status $\left(\chi^{2}=10.8 ; P=.001\right.$; odds ratio $3.75,95 \%$ CI $\left.1.53-9.16\right)$. However, prediction of an adverse postoperative outcome was not improved by including an elevated PAP and/or VFP 


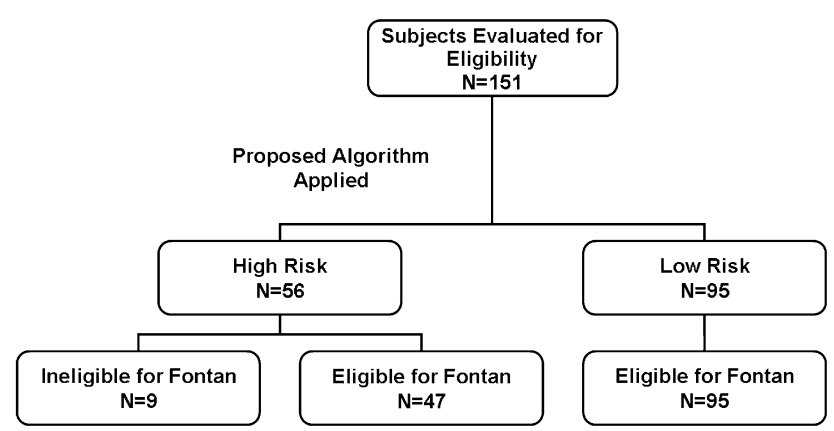

FIGURE 2. Predicting operative eligibility: Results of retrospective testing of the algorithm on 151 children presenting for evaluation before a Fontan operation. All 9 ineligible (inoperable) subjects were correctly classified as high risk. All low-risk subjects were deemed eligible.

as an additional risk factor, and with this modified algorithm, an adverse outcome was not significantly associated with high-risk or low-risk status $\left(\chi^{2}=3.3 ; P=.07\right)$.

Predictors of an adverse outcome. On multivariable modeling, an adverse postoperative outcome, as previously defined, was independently associated with a defined genetic syndrome $(P=.02$, odds ratio $17.7,95 \%$ CI $1.5-208)$, heterotaxy syndrome $(P=.02$, odds ratio $4.7,95 \%$ CI $1.3-$ 17.1), a longer duration of $\mathrm{CPB}(P=.008$, odds ratio $1.01,95 \%$ CI $1.003-1.02$ for 1-minute increase in duration of CPB), and with the absence of a fenestration $(P=.01$, odds ratio $0.29,95 \%$ CI $0.11-0.74$ ). On further analysis to identify predictors of individual adverse outcomes, a longer ICU stay (after logarithmic transformation) was associated with a longer duration of CPB $(P<.0001$, coefficient $=$ $0.006,95 \%$ CI $0.003-0.009$ for 1-minute increase in duration of $\mathrm{CPB})$, heterotaxy syndrome $(P=.01$, coefficient $=$ $0.5,95 \%$ CI $0.11-0.88)$, and a defined genetic syndrome
$(P=.002$, coefficient $0.74,95 \%$ CI $0.08-1.4)$. Longer duration of pleural drainage (after logarithmic transformation) was independently associated with a longer duration of CPB $(P=.002$, coefficient $=0.003,95 \%$ CI $0.001-0.006$ for $1-$ minute increase in duration of $\mathrm{CPB}$ ), heterotaxy syndrome $(P=.04$, coefficient $=0.36,95 \%$ CI $0.01-0.7)$, and the absence of a fenestration $(P=.008$, coefficient $=-0.29,95 \%$ CI -0.49 to -0.08$)$. Notably, there were no significant associations between adverse postoperative outcomes and preoperative hemodynamic measurements (PAP or VFP).

Survival to 1 year. Five subjects died within 1 year after the operation, all of whom were classified in the high-risk group according to the algorithm. The characteristics of these subjects and the clinical events leading to death in each case are shown in Table 5. Four of the 5 had an unbalanced atrioventricular canal defect. All 5 subjects had prominent and often multiple noninvasive risk factors. Three of the 5 subjects had heterotaxy, and 3 had severe atrioventricular valve regurgitation. Only 1 of the 5 had abnormal preoperative hemodynamics. The preoperative PAP was within normal limits in all 5 children and the preoperative VFP was elevated in 1 of the 5 children. On multivariable modeling, the presence of greater than moderate atrioventricular valve regurgitation $(P=.003$, odds ratio 46.3, 95\% CI 3.6-593) and heterotaxy syndrome $(P=.049$, odds ratio $17.3,95 \%$ CI $1.01-172$ ) were independently associated with risk of mortality within 1 year after the Fontan operation. PAP and VFP were not associated with risk of mortality within 1 year.

\section{Interventional Procedures Performed}

Eighty-five transcatheter interventions were performed in $73(48 \%)$ of 135 subjects who subsequently underwent the

TABLE 3. Subjects deemed inoperable for a Fontan operation

\begin{tabular}{|c|c|c|c|c|c|c|}
\hline No & Diagnosis & $\begin{array}{c}\text { PAP } \\
(\mathbf{m m ~ H g})\end{array}$ & $\begin{array}{c}\text { VFP } \\
(\mathbf{m m ~ H g})\end{array}$ & Echo risk factors & $\begin{array}{l}\text { Angiographic } \\
\text { risk factors }\end{array}$ & Clinical risk factors \\
\hline 1 & Unbalanced AVCD & 20 & 12 & $\begin{array}{l}\text { Severe ventricular dysfunction, } \\
\text { prosthetic AV valve stenosis }\end{array}$ & - & - \\
\hline 2 & HLHS & 19 & 18 & - & - & $\begin{array}{l}\text { Chronic lung disease, Noonan } \\
\text { syndrome }\end{array}$ \\
\hline 3 & Unbalanced AVCD & 25 & 18 & $\begin{array}{l}\text { Severe ventricular dysfunction, } \\
\text { moderate AVVR }\end{array}$ & $\begin{array}{r}\text { Left pulmonary } \\
\text { vein stenosis }\end{array}$ & $\begin{array}{l}\text { Chronic lung disease, } \\
\text { tracheostomy }\end{array}$ \\
\hline 4 & Mitral atresia, DORV & 27 & 21 & $\begin{array}{l}\text { Severe AVVR, decreased } \\
\text { ventricular function }\end{array}$ & Hypoplastic RPA & $\begin{array}{l}\text { Chronic lung disease, } \\
\text { tracheostomy }\end{array}$ \\
\hline 5 & $\begin{array}{l}\text { Mitral atresia, DORV, scimitar } \\
\text { syndrome, TAPVC }\end{array}$ & 24 & 13 & - & Scimitar vein & Right lung hypoplasia \\
\hline 6 & HLHS & 10 & 11 & - & Discontinuous LPA & - \\
\hline 7 & HLHS & 14 & 8 & - & LPA occluded by thrombus & - \\
\hline 8 & HLHS & 9 & 8 & - & Occluded SVC & Chronic lung disease \\
\hline 9 & HLHS & 10 & 9 & - & $\begin{array}{l}\text { Severe stenosis of head } \\
\text { and neck vessels }\end{array}$ & - \\
\hline
\end{tabular}

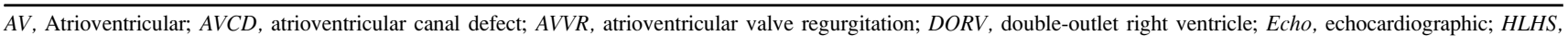
hypoplastic left heart syndrome; $L P A$, left pulmonary artery; $P A P$, pulmonary artery pressure; $R P A$, right pulmonary artery; $S V C$, superior vena cava; $T A P V C$, totally anomalous pulmonary venous connection; $V F P$, ventricular filling pressure. 
TABLE 4. Prediction of adverse postoperative outcomes using the algorithm with and without hemodynamic data

\begin{tabular}{lcc}
\hline & $\begin{array}{c}\text { Proposed } \\
\text { algorithm }\end{array}$ & $\begin{array}{c}\text { Algorithm including } \\
\text { PAP, VFP }\end{array}$ \\
\hline Sensitivity $(95 \% \mathrm{CI})$ & $51 \%(34 \%-69 \%)$ & $62 \%(45 \%-79 \%)$ \\
Specificity $(95 \% \mathrm{CI})$ & $78 \%(68 \%-86 \%)$ & $55 \%(45 \%-65 \%)$ \\
PPV $(95 \% \mathrm{CI})$ & $45 \%(29 \%-62 \%)$ & $29 \%(19 \%-40 \%)$ \\
NPV $(95 \% \mathrm{CI})$ & $82 \%(73 \%-89 \%)$ & $81 \%(70 \%-89 \%)$ \\
High-risk status & & \\
Likelihood ratio & 2.32 & 1.37 \\
Pre-test probability & $26 \%$ & $26 \%$ \\
Post-test probability & $45 \%$ & $25.4 \%$ \\
Low-risk status & \multicolumn{2}{|}{} \\
Likelihood ratio & 0.63 & 0.69 \\
Pre-test probability & $26 \%$ & $26 \%$ \\
Post-test probability & $18 \%$ & $20 \%$ \\
\hline
\end{tabular}

$\overline{C I \text {, Confidence interval; } N P V \text {, negative predictive value; } P A P \text {, pulmonary artery pres- }}$ sure; $P P V$, positive predictive value; $V F P$, ventricular filling pressure.

Fontan operation. A majority of these interventions included embolization of aortopulmonary collateral arteries $(n=64$, $75 \%$ ). Other procedures performed included embolization of venovenous collaterals $(\mathrm{n}=15)$, stenting of pulmonary artery stenosis $(\mathrm{n}=3)$, angioplasty for recurrent coarctation of the aorta $(\mathrm{n}=2)$, and embolization of a right ventricular sinusoid $(\mathrm{n}=1)$. Interventions were performed in $23(58 \%)$ of 40 subjects in the high-risk group and in $50(56 \%)$ of 90 subjects in the low-risk group. No relationship was seen between the performance of an intervention and an adverse postoperative outcome.

\section{DISCUSSION}

In this study, we proposed and evaluated a diagnostic algorithm that does not use routine cardiac catheterization for low-risk subjects before the Fontan operation. In a retrospective evaluation, the proposed algorithm was successful as a screening tool to identify subjects who are inoperable. In addition, adverse postoperative outcomes, including death within 1 year after the operation, were not associated with preoperative hemodynamic parameters; hence if such an algorithm were used to screen patients, the omission of routine invasive hemodynamic measurements would not impair the ability to predict adverse early postoperative outcomes.

\section{Identifying Inoperable Subjects}

In identifying subjects who are inoperable, the proposed algorithm is highly sensitive $(100 \%)$ but has a low specificity $(67 \%)$. To maintain a high level of sensitivity, we chose to use a low threshold for classifying a subject as high risk ( $\geq 1$ risk factor), and this likely resulted in a low specificity. However, this low specificity is acceptable because this algorithm is being proposed only as a screening tool to identify high-risk patients who would then undergo invasive testing. Notably, the inoperable subjects had relatively prominent and often multiple risk factors and all were classified as high risk according to the proposed algorithm. Furthermore, inoperable status was rare $(6 \%)$, likely resulting from a consistent policy of staged palliation and the rarity of pulmonary vascular disease. If the proposed algorithm were used to screen subjects who require cardiac catheterization, all the inoperable subjects would be correctly classified as high risk and would undergo cardiac catheterization. It should be noted that these results are based on the assumption that MRI or CT imaging is equivalent to conventional $\mathrm{x}$-ray angiography.

\section{Predicting Adverse Postoperative Outcomes}

In addition to assessing eligibility, prediction of adverse postoperative outcomes is another goal of preoperative testing. In this study, we found that the proposed diagnostic algorithm allowed modest prediction of adverse postoperative

TABLE 5. Mortality within 1 year

\begin{tabular}{|c|c|c|c|c|c|c|c|}
\hline \multirow[b]{2}{*}{ No. } & \multirow[b]{2}{*}{$\begin{array}{c}\text { Age at } \\
\text { Fontan }(y)\end{array}$} & \multirow[b]{2}{*}{ Diagnosis } & \multirow[b]{2}{*}{$\begin{array}{l}\text { Nonhemodynamic } \\
\text { risk factors }\end{array}$} & \multicolumn{2}{|c|}{ Preoperative hemodynamics (mm Hg) } & \multirow{2}{*}{$\begin{array}{c}\text { Timing of } \\
\text { death (days } \\
\text { after Fontan) } \\
\end{array}$} & \multirow[b]{2}{*}{$\begin{array}{c}\text { Clinical events related } \\
\text { to mortality }\end{array}$} \\
\hline & & & & PAP & VFP & & \\
\hline 1 & 1.7 & $\begin{array}{l}\text { Unbalanced } \\
\text { AVCD }\end{array}$ & $\begin{array}{l}\text { Trisomy } 21, \\
\text { severe AVVR }\end{array}$ & 12 & 10 & 89 & $\begin{array}{l}\text { Prolonged pleural effusion, thrombus } \\
\text { in Fontan pathway, sepsis }\end{array}$ \\
\hline 2 & 3.8 & $\begin{array}{c}\text { Unbalanced } \\
\text { AVCD }\end{array}$ & Heterotaxy & 12 & 9 & 90 & $\begin{array}{l}\text { Prolonged pleural and pericardial } \\
\text { effusion, thrombus in Fontan } \\
\text { pathway }\end{array}$ \\
\hline 3 & 7 & $\begin{array}{l}\text { Unbalanced } \\
\text { AVCD }\end{array}$ & Heterotaxy & 13 & 9 & 25 & Low cardiac output, renal failure, JET \\
\hline 4 & 2 & $\begin{array}{l}\text { Unbalanced } \\
\text { AVCD }\end{array}$ & $\begin{array}{l}\text { Heterotaxy, } \\
\text { severe AVVR }\end{array}$ & 10 & 7 & 22 & $\begin{array}{l}\text { Low cardiac output, respiratory } \\
\text { failure. }\end{array}$ \\
\hline 5 & 2 & HLHS & $\begin{array}{l}\text { Severe AVVR, } \\
\text { occluded LPA }\end{array}$ & 9 & 5 & 80 & Prolonged pleural effusion \\
\hline
\end{tabular}

$\overline{A V C D}$, Atrioventricular canal defect; $A V V R$, atrioventricular valve regurgitation; $H L H S$, hypoplastic left heart syndrome; $J E T$, junctional ectopic tachycardia; $L P A$, left pulmonary artery; $P A P$, pulmonary artery pressure; $V F P$, ventricular filling pressure. 
events but, more importantly, the addition of invasive hemodynamic parameters to this algorithm did not improve this prediction. Hence, if the proposed algorithm was used to screen subjects who require cardiac catheterization, the omission of routine invasive hemodynamic testing in the low-risk subjects would not impair the ability to predict adverse postoperative outcomes. Previous studies have demonstrated that invasive hemodynamic parameters can be used to predict postoperative outcomes..$^{9-12}$ However, in our study, we did not find a significant relationship between preoperative invasive hemodynamic parameters and postoperative outcomes. In fact, we found that adverse early postoperative outcomes were associated with nonhemodynamic factors such as the presence of heterotaxy or genetic syndromes and the duration of CPB. Hemodynamic parameters also were not predictive of mortality within 1 year. The only predictors of mortality were the presence of greater than moderate atrioventricular valve regurgitation and heterotaxy syndrome. The lack of association between preoperative hemodynamics and adverse postoperative outcomes may be related to a consistent policy of timely staged palliation in the current surgical era and the resultant rarity of significantly elevated PAP or VFP.

\section{Interventional Procedures}

In addition to assessment of eligibility and prediction of postoperative outcomes, cardiac catheterization also provides an opportunity for interventional procedures before the Fontan operation. In a significant proportion of our study population $(48 \%)$, an intervention was performed during cardiac catheterization, which most frequently $(75 \%)$ consisted of embolization of aortopulmonary collateral vessels. The clinical utility of routine embolization of small aortopulmonary collateral vessels is not known. Data both supporting and criticizing this practice have been presented by various investigators; hence, this practice is of unproven benefit. $^{20-25}$ With the proposed algorithm, subjects with significant aortopulmonary collaterals would be identifiable using noninvasive angiography and subsequent coil embolization could be performed if deemed necessary. Further investigation is needed to determine whether embolization of small aortopulmonary collateral vessels improves clinical outcomes.

\section{Study Limitations}

This study had several important limitations. First, the study is limited by its retrospective design. Hence, although the algorithm would omit cardiac catheterization for lowrisk subjects, all the patients in this study underwent cardiac catheterization. Second, although data obtained with noninvasive angiographic techniques such as MRI or CT are a component of the proposed diagnostic algorithm, the accuracy of MRI or CT was not directly compared with x-ray angiography, although this has been demonstrated previously by several investigators in children with complex congenital heart disease, including those with a functionally single ventricle. ${ }^{2-6,16}$ A recently published randomized trial found that cardiac MRI is a safe, effective, and less costly alternative to routine catheterization in the evaluation of selected patients before a bidirectional Glenn operation. ${ }^{16}$ Third, follow-up beyond 1 year after the operation was not available for this study and hence long-term outcomes were not evaluated. Finally, the effect of interventional procedures such as the coiling of aortopulmonary collateral arteries in low-risk patients, while controversial, was not assessed in this study. Although the long-term benefit of these interventions in low-risk subjects has not been established, it is not known whether eliminating cardiac catheterization and interventional procedures would affect outcome.

\section{CONCLUSION}

In summary, we have shown that a noninvasive diagnostic algorithm such as the one proposed here could potentially be used as a screening tool to identify subjects who are inoperable for a Fontan procedure. Second, our results indicate that preoperative hemodynamic parameters are not associated with early postoperative outcomes. Adverse postoperative outcomes were associated with risk factors identified on medical history, such as heterotaxy and genetic syndromes. Hence, the omission of routine cardiac catheterization in low-risk subjects would not impair identification of inoperable subjects or those at risk for adverse early postoperative outcomes. The use of the proposed algorithm could help avoid the risk of cardiac catheterization and reduce the cost of evaluation in low-risk subjects while allowing the opportunity for invasive hemodynamic testing and/or interventional procedures in high-risk subjects. Owing to the retrospective nature of this study and because MRI or CT imaging was not performed in our subjects, the results should be considered preliminary until further prospective validation of such a strategy is performed. It should be noted that high-quality MRI or CT imaging is necessary if such a strategy is used. Finally, further investigation is warranted to identify other predictors of adverse outcomes after the Fontan operation and to evaluate whether routine embolization of small aortopulmonary collateral arteries improves outcomes.

\section{References}

1. Fontan F, Baudet E. Surgical repair of tricuspid atresia. Thorax. 1971;26:240-8

2. Greil GF, Powell AJ, Gildein HP, Geva T. Gadolinium-enhanced three-dimensional magnetic resonance angiography of pulmonary and systemic venous anomalies. J Am Coll Cardiol. 2002;39:335-41.

3. Geva T, Greil GF, Marshall AC, Landzberg M, Powell AJ. Gadolinium-enhanced 3-dimensional magnetic resonance angiography of pulmonary blood supply in patients with complex pulmonary stenosis or atresia: comparison with x-ray angiography. Circulation. 2002;106:473-8.

4. Lee T, Tsai IC, Fu YC, Jan SL, Wang CC, Chang Y, et al. Using multidetectorrow $\mathrm{CT}$ in neonates with complex congenital heart disease to replace diagnostic cardiac catheterization for anatomical investigation: initial experiences in technical and clinical feasibility. Pediatr Radiol. 2006;36:1273-82. 
5. Greil GF, Schoebinger M, Kuettner A, Schaefer JF, Dammann F, Claussen CD, et al. Imaging of aortopulmonary collateral arteries with high-resolution multidetector CT. Pediatr Radiol. 2006;36:502-9.

6. Prakash A, Torres AJ, Printz BF, Prince MR, Nielsen JC. Usefulness of magnetic resonance angiography in the evaluation of complex congenital heart disease in newborns and infants. Am J Cardiol. 2007;100:715-21.

7. Garofalo CA, Cabreriza SE, Quinn TA, Weinberg AD, Printz BF, Hsu DT, et al. Ventricular diastolic stiffness predicts perioperative morbidity and duration of pleural effusions after the Fontan operation. Circulation. 2006;114(1 Suppl). I56-61.

8. Ro PS, Rychik J, Cohen MS, Mahle WT, Rome JJ. Diagnostic assessment before Fontan operation in patients with bidirectional cavopulmonary anastomosis: are noninvasive methods sufficient? J Am Coll Cardiol. 2004;44:184-7.

9. Gaynor JW, Bridges ND, Cohen MI, Mahle WT, Decampli WM, Steven JM, et al. Predictors of outcome after the Fontan operation: is hypoplastic left heart syndrome still a risk factor? J Thorac Cardiovasc Surg. 2002;123:237-45.

10. Cetta F, Feldt RH, O'Leary PW, Mair DD, Warnes CA, Driscoll DJ, et al. Improved early morbidity and mortality after Fontan operation: the Mayo Clinic experience, 1987 to 1992. J Am Coll Cardiol. 1996;28:480-6.

11. Annecchino FP, Brunelli F, Borghi A, Abbruzzese P, Merlo M, Parenzan L. Fontan repair for tricuspid atresia: experience with 50 consecutive patients. Ann Thorac Surg. 1988;45:430-6.

12. Culbertson CB, George BL, Day RW, Laks H, Williams RG. Factors influencing survival of patients with heterotaxy syndrome undergoing the Fontan procedure. J Am Coll Cardiol. 1992;20:678-84.

13. Atz AM, Cohen MS, Sleeper LA, McCrindle BW, Lu M, Prakash A, et al. Functional state of patients with heterotaxy syndrome following the Fontan operation. Cardiol Young. 2007;17(Suppl. 2):44-53.

14. Bartz PJ, Driscoll DJ, Dearani JA, Puga FJ, Danielson GK, O'Leary PW, et al. Early and late results of the modified Fontan operation for heterotaxy syn- drome: 30 years of experience in 142 patients. J Am Coll Cardiol. 2006;48 2301-5.

15. Kim SJ, Kim WH, Lim HG, Lee CH, Lee JY. Improving results of the Fontan procedure in patients with heterotaxy syndrome. Ann Thorac Surg. 2006;82:1245-51.

16. Brown DW, Gauvreau K, Powell AJ, Lang P, Colan SD, Del Nido PJ, et al. Cardiac magnetic resonance versus routine cardiac catheterization before bidirectional Glenn anastomosis in infants with functional single ventricle: a prospective randomized trial. Circulation. 2007;116:2718-25.

17. Deeks JJ, Altman DG. Diagnostic tests 4: likelihood ratios. BMJ. 2004;329:168-9.

18. Akobeng AK. Understanding diagnostic tests 1 : sensitivity, specificity and predictive values. Acta Paediatr. 2007;96:338-41.

19. Akobeng AK. Understanding diagnostic tests 2 : likelihood ratios, pre- and posttest probabilities and their use in clinical practice. Acta Paediatr. 2007;96:487-91.

20. Bradley SM. Management of aortopulmonary collateral arteries in Fontan patients: routine occlusion is not warranted. Semin Thorac Cardiovasc Surg Pediatr Card Surg Annu. 2002;5:55-67.

21. Bradley SM, McCall MM, Sistino JJ, Radtke WA. Aortopulmonary collatera flow in the Fontan patient: does it matter? Ann Thorac Surg. 2001;72:408-15.

22. Ichikawa H, Yagihara T, Kishimoto H, Isobe F, Yamamoto F, Nishigaki K, et al. Extent of aortopulmonary collateral blood flow as a risk factor for Fontan operations. Ann Thorac Surg. 1995;59:433-7.

23. Kanter KR, Vincent RN. Management of aortopulmonary collateral arteries in Fontan patients: occlusion improves clinical outcome. Semin Thorac Cardiovasc Surg Pediatr Card Surg Annu. 2002;5:48-54

24. Spicer RL, Uzark KC, Moore JW, Mainwaring RD, Lamberti JJ. Aortopulmonary collateral vessels and prolonged pleural effusions after modified Fontan procedures. Am Heart J. 1996;131:1164-8.

25. Triedman JK, Bridges ND, Mayer JE Jr, Lock JE. Prevalence and risk factors for aortopulmonary collateral vessels after Fontan and bidirectional Glenn procedures. J Am Coll Cardiol. 1993;22:207-15. 